\title{
When doctors turn to crowdfunding to meet patients' needs
}

n Cite as: CMAJ 2019 June 24;191:E719-20. doi: 10.1503/cmaj.109-5766

Posted on cmajnews.com on June 5, 2019.

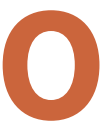

ne morning recently in Kentville, Nova Scotia, emergency physicians Dr. Keith MacCormick and Dr. Rebecca Brewer arrived at Valley Regional Hospital and saw on the whiteboard that two-dozen inpatients were still in emergency department beds.

"We'd never seen anything like that," MacCormick said. They had seen overcrowding before, but this felt like a crisis.

The 24 inpatients were crammed into 20 clinical rooms. Few beds were left for incoming emergency patients. Brewer recalls people with low mobility and serious illnesses being told they had to get off stretchers and return to the waiting room.
The dire situation drove MacCormick, Brewer and fellow emergency physician Dr. Robert Miller to take an unusual step. They launched a GoFundMe page to raise money for new long-term care beds in the Annapolis Valley. They're a long way from their goal of $\$ 100000$, and even if they reach it, the physicians acknowledge it wouldn't go far. But they're hoping the campaign will inspire action.

The GoFundMe was "kind of an act of desperation to try and get a message out to the government," said Miller.

At any given time, as many as $20 \%$ of acute-care beds in Nova Scotia are occupied by patients needing long-term care.
Premier Stephen McNeil's government has not opened any new long-term care beds since being elected in 2013. According to Andrew Preeper, a spokesperson for the Department of Health and Wellness, the province's emphasis is on home care, on which they've increased spending by $\$ 40$ million over the past five years.

Jeremy Snyder, a bioethicist at Simon Fraser University who researches medical crowdfunding, has seen patients drive policy change by shaming governments into action before but it's rare to see doctors behind such a campaign. "The idea that you'd have to crowdfund to get basic care in Canada is really powerful," said Snyder.

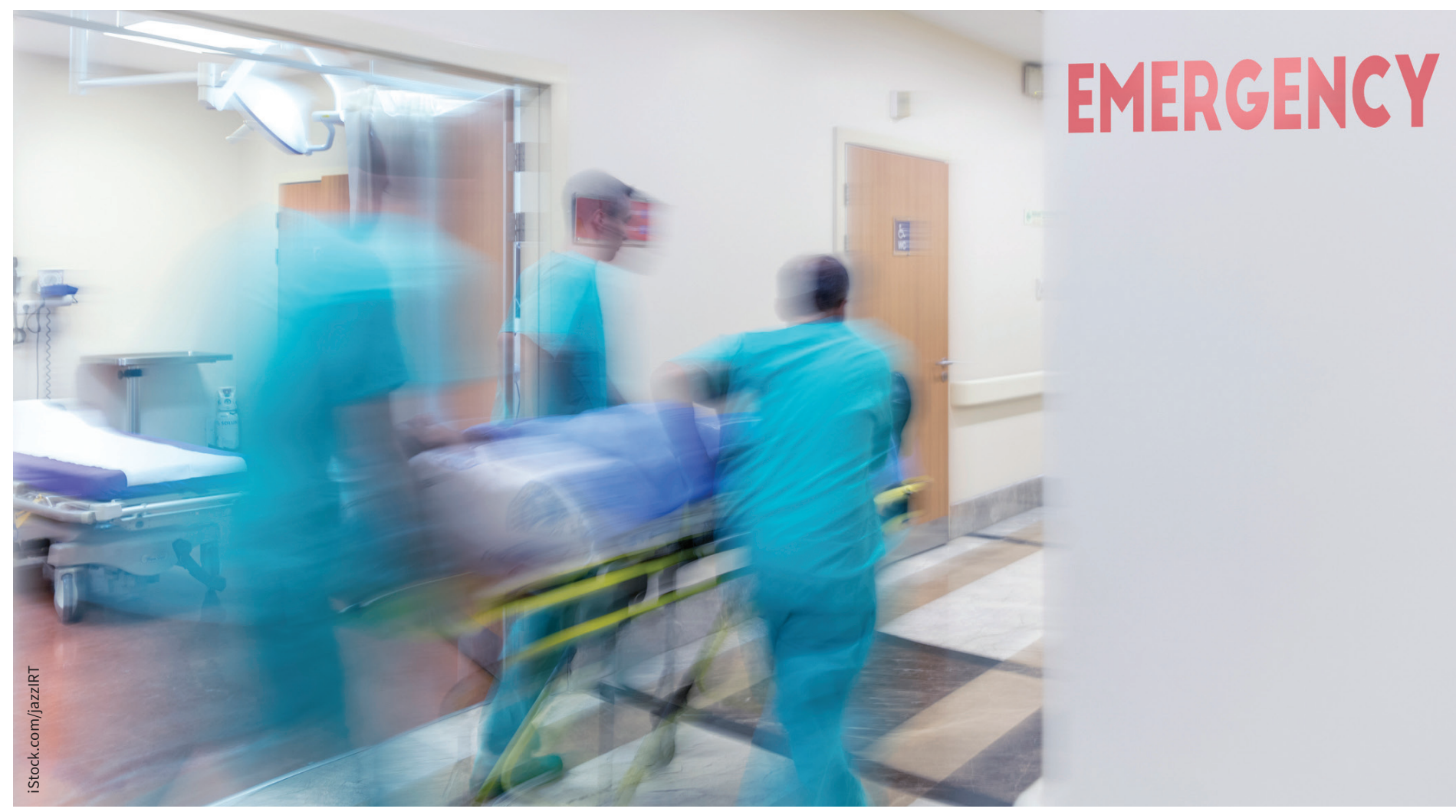

It can be difficult to treat emergency patients if the ED is full of inpatients. 
Snyder thinks the emergency physicians' campaign could be improved by making it clearer where the money will go. They could also include information about the issue and the names of relevant government officials on their GoFundMe page, should people want to contact them.

Still, Snyder doesn't see crowdfunding as an effective means of addressing medical needs. He points to research showing that crowdfunding tends to raise money in inequitable ways. It creates a kind of popularity contest and people of higher socioeconomic status tend to benefit most.

A recent study led by Martin Lukk, a sociologist at the University of Toronto, analyzed 319 crowdfunding campaigns and found that Canadians who are older or from visible minorities tend to raise less money. Crowdfunding "reproduces offline inequalities with potentially perilous consequences for democratic life and individual suffering," concluded the authors.

Another common criticism is that crowdfunding doesn't address the under- lying issues that impede access to care. If crowdfunding can help someone afford their prescriptions, "that's great, but that doesn't necessarily help the people behind [them]," said Snyder.

But crowdfunding could potentially be used as a platform to achieve broader goals, by bringing attention to a problem and facilitating advocacy for policy change. This appears to be part of the motivation for the Nova Scotia campaign. The doctors acknowledge, however, that they're not experts on fundraising or getting media attention - they're full-time emergency department doctors. "It's just getting to the point where our desperation means that even the imperfect is all we have right now," Brewer said.

Dr. Mark Taylor, an executive medical director with the Nova Scotia Health Authority, understands the physicians' frustrations. He had met with Miller, MacCormick and other emergency physicians earlier to discuss the issues they are facing. Although he acknowledged that a lack of long-term care beds may play a role in overcrowding, Taylor said that "simply adding more beds is not in and of itself the panacea." Instead, Taylor suggested, the focus should be on getting patients out of hospital more effectively and improving home care services.

Katherine Fierlbeck, a political science professor at Dalhousie University, sees the GoFundMe campaign as a response to structural issues and doctors feeling the government isn't listening to them. The relationship between physicians and the provincial health authority is indeed strained. The Chronicle Herald recently obtained a survey in which $72 \%$ of responding physicians said they didn't trust the Nova Scotia Health Authority.

In terms of long-term care, Fierlbeck said, Nova Scotia is doing particularly poorly because it has an older population and a stagnant number of beds. Still, she stressed that this is just one aspect of a "roiling, tumultuous debate over access to health care" in Nova Scotia.

Caroline Mercer, Toronto, Ont. 